Article

\title{
Integrated Traction Control Strategy for Distributed Drive Electric Vehicles with Improvement of Economy and Longitudinal Driving Stability
}

\author{
Xudong Zhang * and Dietmar Göhlich \\ Methods for Product Development and Mechatronics, Technical University of Berlin, 10623 Berlin, Germany; \\ dietmar.goehlich@tu-berlin.de \\ * Correspondence: xudong.zhang@campus.tu-berlin.de \\ Academic Editor: K.T. Chau \\ Received: 5 October 2016; Accepted: 3 January 2017; Published: 19 January 2017
}

\begin{abstract}
This paper presents an integrated traction control strategy (ITCS) for distributed drive electric vehicles. The purpose of the proposed strategy is to improve vehicle economy and longitudinal driving stability. On high adhesion roads, economy optimization algorithm is applied to maximize motors efficiency by means of the optimized torque distribution. On low adhesion roads, a sliding mode control (SMC) algorithm is implemented to guarantee the wheel slip ratio around the optimal slip ratio point to make full use of road adhesion capacity. In order to avoid the disturbance on slip ratio calculation due to the low vehicle speed, wheel rotational speed is taken as the control variable. Since the optimal slip ratio varies according to different road conditions, Bayesian hypothesis selection is utilized to estimate the road friction coefficient. Additionally, the ITCS is designed for combining the vehicle economy and stability control through three traction allocation cases: economy-based traction allocation, pedal self-correcting traction allocation and inter-axles traction allocation. Finally, simulations are conducted in CarSim and Matlab/Simulink environment. The results show that the proposed strategy effectively reduces vehicle energy consumption, suppresses wheels-skid and enhances the vehicle longitudinal stability and dynamic performance.
\end{abstract}

Keywords: traction control; longitudinal dynamics; electric vehicle; slip ratio control; vehicle economy

\section{Introduction}

During the past years, due to the energy crisis and environmental concerns, electric vehicles (EVs) have become a fast-growing hotspot [1]. With the improvements on the electric motor and motor controller technology, many possibilities of power train configurations have been proposed [2,3]. One of the latest configurations is known as distributed drive electric vehicles (DDEVs), which employ four motors that are integrated to each wheel and controlled independently. This configuration has many advantages such as quick and accurate torque response, easier torque and revolutions per minute (RPM) measurement, and independent control for one single motor, which provides a broad prospect for vehicle dynamic improvement [4].

Traction control is a significant aspect of vehicle dynamic control and greatly influences vehicle stability, safety and even economy. Therefore, much research has been carried out so far focusing on this area [5-9]. Logic threshold control is widely adopted in most of the mature Anti-lock Braking System (ABS) products [10]. However, its low adaptability and precision is also apparent. Fuzzy control algorithm has been applied to traction control research in EVs [11]. A maximum torque estimator was designed to achieve the anti-slip control [12]. This method only needs the driving wheels' torque and 
RPM information instead of vehicle body velocity. Besides, model following control (MFC) and slip ratio control (SRC) were designed in traction control systems, which were verified through simulation and field test [13]. Due to its robustness, sliding mode control (SMC) has increasingly been applied in vehicle traction control [14-16]. Drakunov et al. [17] and Ünsal et al. [18] applied SMC to maintain the wheel slip at any given value. Wen et al. [19] presented an acceleration slip regulation strategy based on SMC. In this research, slip ratio calculation formula in the form of a state equation is used for solving the numerical problem caused by the traditional way. From the perspective of vehicle economy, Nam [20] proposed a traction-ability and energy efficiency improvement method using wheel slip control. However, the energy consumption only led by unnecessary wheel spin can be reduced. Yuan [21] utilized the independent characteristics of traction motors to develop a torque distribution method for decreasing EV energy. Furthermore, quite a few cost function-based traction allocation approaches have been carried out. Mokhiamar and Abe [22,23] proposed an allocation algorithm that minimizes the weighted sum square of the workload of four wheels. However, this cost function cannot guarantee every tire is fully used. Sometimes, one tire is already nearing its limit while the workload of others is relatively low, which impedes the further improvement of vehicle stability. Addressing this drawback, He and Hori [24] and Nishihara and Kumamoto [25] proposed a minimax control allocation that minimizes the utilization of the tire with maximum workload. Yamakawa et al. [26] proposed an optimal torque allocation algorithm using the changeable principle to minimize the dissipation energy produced by the tires on the contact with the ground. It can reduce the tire slippage and transmit motor torques to the ground efficiently. However, due to the large calculation cost, it is difficult to guarantee the real-time performance of the above algorithms.

Additionally, it is should be noted that the performance of vehicle traction allocation methods is highly relied on the friction force arising from the contact of tires and the road surface. Therefore, an adequate knowledge of the tire-road friction coefficient is of great importance. Under consideration of the fairly easy and cost-effective implementation, the estimation approaches using vehicle dynamic response information has drawn increasing interest recently. In [27], a road friction coefficient estimation method was introduced based on extend Kalman filter and neural network. Simulation results show that under uncritical driving conditions it has a good performance. Guan et al. [28] presented a maximum friction coefficient estimator by comparing the samples of the estimated values with the standard one of each typical road, and using the minimum statistical error as the recognition principle to improve identification robustness.

Most control strategies are incomplete, for they only focus on either stability or energy saving, while taking insufficient account of different road conditions. The major contribution of the presented integrated traction control strategy (ITCS) in this paper is given as follows:

(1) Propose an economy-based traction allocation method;

(2) Apply Bayes' theorem to determine the optimal slip ratio under a specific road surface;

(3) Design a sliding mode controller to track the desired optimal slip ratio;

(4) Build a framework integrating vehicle economy and longitudinal stability control with three traction allocation cases (economy-based traction allocation, pedal self-correcting traction allocation and inter-axles traction allocation).

The economy-based traction allocation is developed using an objective function of minimizing power loss of four electric motors, which does not rely on the complex online computation. It is obtained via an offline optimization procedure and utilized for online allocation by simple interpolation. The low calculation effort makes it easy to implement the algorithm on real vehicles. Subsequently, SMC is used to calculate the torque which can make the tire under the optimal slip ratio point. In order to avoid the deterioration of direct SRC in the low speed region, the proposed control strategy takes wheel angular velocity as control variable. Finally, the effectiveness of the ITCS for both energy saving and longitudinal stability is validated via the co-simulation of CarSim (Version 9.0.3, Mechanical 
Simulation Corporation, Ann Arbor, MI, USA) and Matlab/Simulink (Version 2012b, MathWorks, Natick, MA, USA).

This paper proceeds as follows. Section 2 presents the DDEV system modeling. In Section 3, the integrated control strategy is developed, which contains economy-based and stability-based algorithms. Section 4 performs numerical simulations for different control cases. Finally, some conclusions are drawn in Section 5.

\section{System Modeling}

In this section, an EV dynamic model is established using CarSim and Matlab/Simulink, which is driven by four independently controlled DC motors. The chassis layout is shown in Figure 1. The controller acquires torque and RPM signals from four motors, and then sends them the torque command signals.

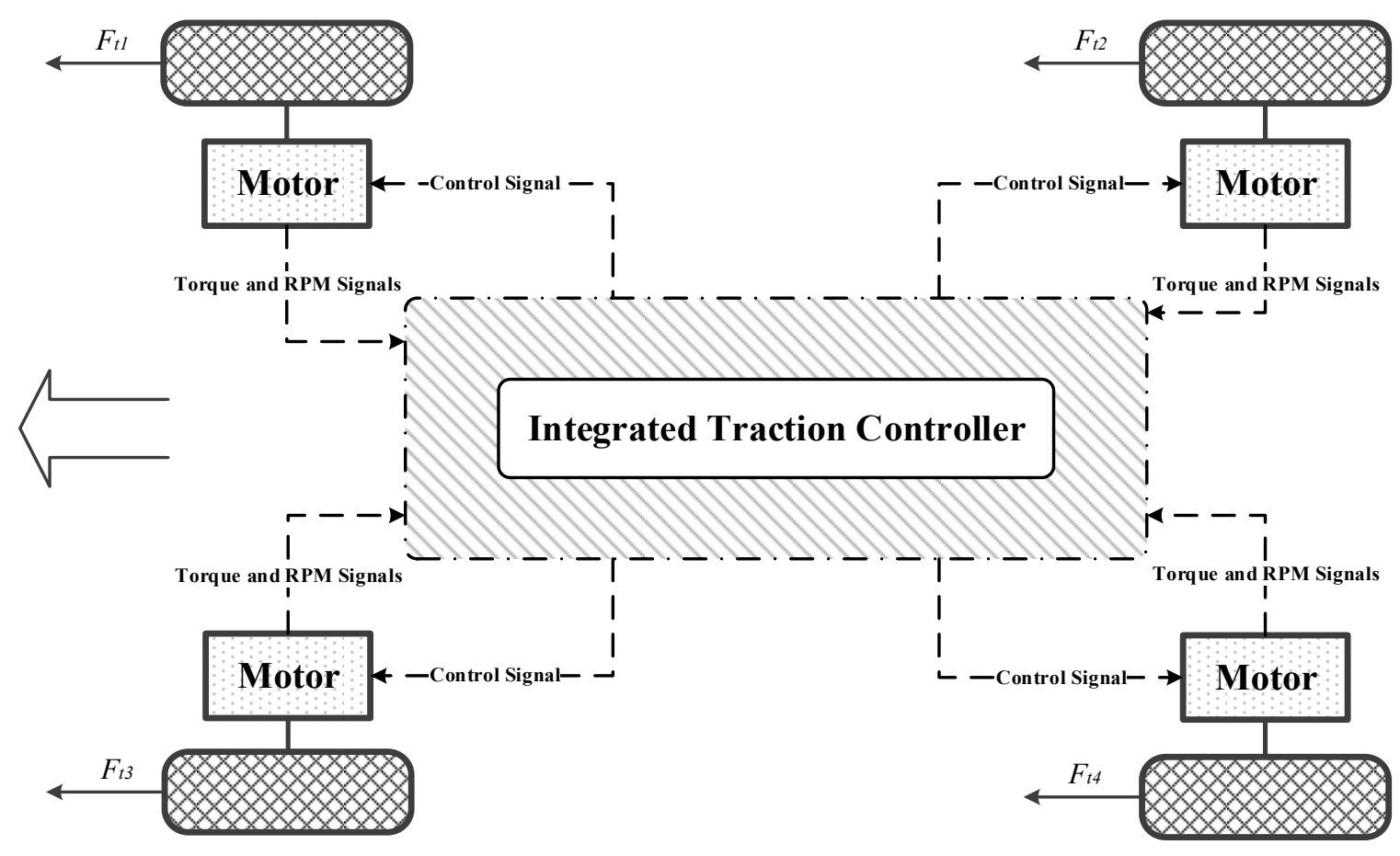

Figure 1. Chassis and traction control system layout. RPM: revolutions per minute.

\subsection{Vehicle Dynamics Model}

A detailed and comprehensive vehicle model must be used to accurately simulate the vehicle response under various maneuvers. Therefore, commercial vehicle dynamics software CarSim is adopted in this study. The embedded vehicle model in CarSim, containing driver model, brakes, steering system, "Pacejka 5.2" tire model, and suspension components, is used to simulate the real vehicle.

\subsection{Motor Model}

For DDEVs, each wheel is individually driven by a DC motor through a fixed reduction gear. The motor torque external characteristics and efficiency map are shown in Figure 2 [29].

The motor's torque response can be simplified as first-order inertia as the following equation:

$$
T_{i}=\frac{T_{c m d i}}{t s+1}
$$

where $T_{i}$ is the motor torque output; $T_{c m d i}$ is the torque command signal; and $t$ is the time constant. 
Since motor power is the function of motor efficiency, rotational speed and torque output, based on the efficiency map in Figure 2, the motor power can be easily calculated as:

$$
P_{i}=\frac{n_{i} \cdot T_{i}}{\eta_{i}\left(T_{i}, n_{i}\right)}
$$

where $P_{i}$ and $n_{i}$ denote the motor power and rotational speed. $\eta_{i}$ is the efficiency for four motors which can be obtained from Figure 2 with current torque and RPM signals.

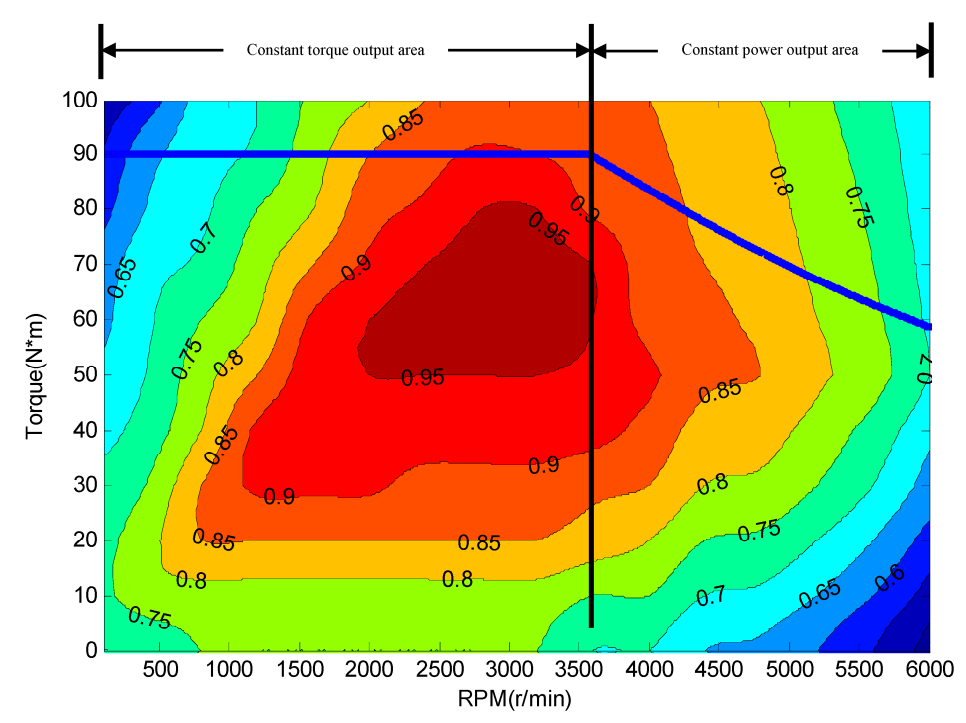

Figure 2. Motor torque external characteristics and efficiency map.

For each wheel, the driving equation is given as:

$$
I_{i} \cdot \dot{\omega}=T_{i} \cdot b e t a-F_{t i} \cdot r
$$

where $I_{i}$ is the wheel inertia; $r$ is the wheel radius; beta is the reducer ratio; and $F_{t i}$ is wheel longitudinal force.

\section{Integrated Control Strategy Design}

Under the premise of ensuring vehicle stability, its economy performance needs to be improved as much as possible, for EVs are developed to be a solution to the energy crisis. In order to achieve that, two traction control algorithms are discussed in the following subsections. One is for economy promotion, and the other is aimed at guaranteeing the vehicle longitudinal stability. Finally, to combine them together through three traction allocation cases, the integrated control strategy is introduced and its schematic is illustrated in Figure 3.

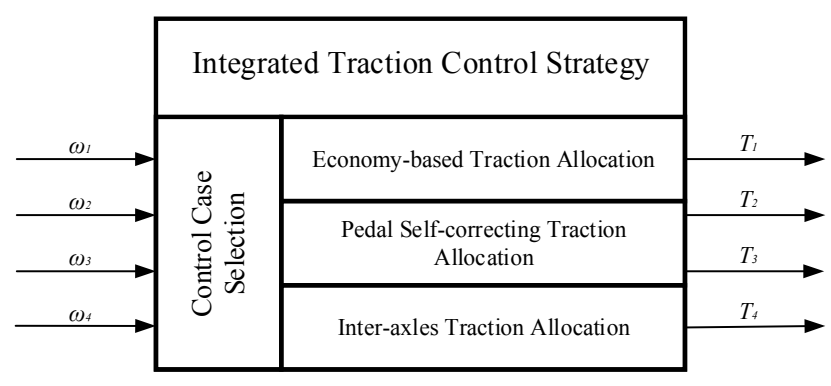

Figure 3. Schematic of the proposed integrated control strategy. 


\subsection{Economy Control}

\subsubsection{Objective Functions Establishment}

The relationship among the motor's torque, RPM and efficiency is shown in Figure 2. It can be seen that the motor efficiency is quite distinguishing in different working regions and especially when it works in the low speed or low torque output region, the motor has poor efficiency.

(1) When a vehicle is running at high speed and the driving torque is distributed equally to the four wheels in the most common way, according to Figure 2, for one single motor it must be poorly efficient because of its low torque output. Oppositely, if we use front-wheel-drive (FWD) or rear-wheel-drive (RWD) instead of four-wheel-drive (4WD), then the motor torque output will increase about twice the original. That means the motor works more efficiently.

(2) When a vehicle starts accelerating with high torque, the driving torque is only distributed to the front or rear wheels, which is also a very low efficiency allocation way. According to Figure 2, in this case, $4 \mathrm{WD}$ is an obviously better pattern.

According to the above qualitative analysis, a single distribution pattern cannot meet the actual vehicle economy demand. If the driving torque can be real-time distributed among four motors according to motor operating conditions, then motors efficiency will be improved [30]. The following objective functions are established:

$$
\min J_{d}=\sum_{i=1-4}^{4} P_{i}=\sum_{i=1-4}^{4} \frac{n_{i} \cdot T_{i}}{\eta_{i}\left(T_{i}, n_{i}\right)}
$$

The objective functions should satisfy the following equality constraints and inequality constraints, the desired driving torque $T_{d}$, understeer characteristics, the motor properties, and a few assumptions.

$$
\begin{gathered}
\text { s.t. } \sum_{i=1-4}^{4} T_{i}=T_{d} \\
T_{1}+T_{3} \geq T_{2}+T_{4} \\
\left|T_{i}\right| \leq\left|T_{\text {motor }}\right|
\end{gathered}
$$

where $T_{\text {motor }}$ is the motor maximum torque.

In order to simplify the calculation, a few assumptions are listed here.

(1) The slip ratio and rotational speed difference of each wheel is quite small.

(2) The torque output is identical if the motors are on the same axle.

Despite its simplification, these assumptions are still justified, since only longitudinal dynamic is discussed in this study and economy control will be activated only when the controller is fully sure that the car runs stable.

The assumptions can be formulated as:

$$
\begin{gathered}
T_{1}=T_{3}=T_{f} / 2=p \cdot T_{d} / 2 \\
T_{2}=T_{4}=T_{r} / 2=(1-p) \cdot T_{d} / 2 \\
n=\text { bet } \cdot \frac{u}{r} \cdot \frac{30}{\pi}
\end{gathered}
$$

where $p \in[0.5,1]$ is economy distribution coefficient; $T_{f}$ is the front axle driving torque; $T_{r}$ is the rear axle driving torque; and $u$ is the vehicle longitudinal velocity. 
Then, the final economy objective function is obtained:

$$
J_{d}=n \cdot\left\{\frac{p \cdot T_{d}}{\eta\left[\frac{p \cdot T_{d}}{2}, n\right]}+\frac{(1-p) \cdot T_{d}}{\eta\left[\frac{(1-p) \cdot T_{d}}{2}, n\right]}\right\}
$$

\subsubsection{Solutions to Objective Functions}

In this paper, genetic algorithm is applied to solve these discontinuous objective functions. It can effectively prevent local optimization and find the solutions accurately and rapidly.

The objective function solution $p$ is given as a two-dimensional lookup table with current desired driving torque and motor rotational speed, which can avoid numerous online calculations and meet system real-time requirements. The economy distribution coefficient $p$ is shown in Figure 4 .

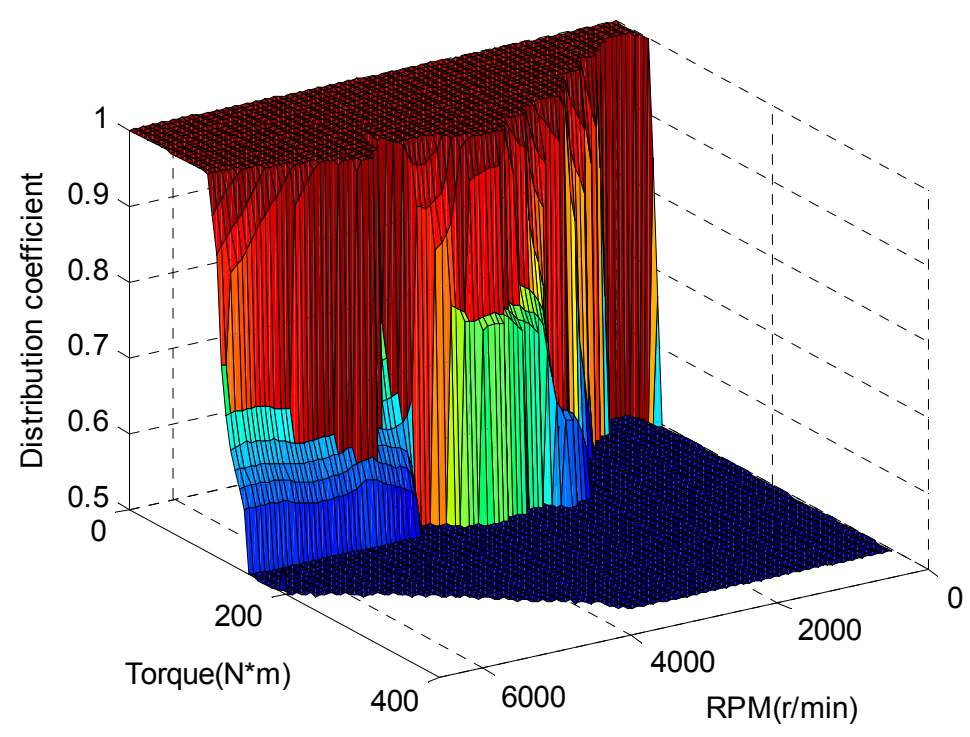

Figure 4. Economy distribution coefficient map.

For one single control cycle, the driver desired torque $T_{d}$ and motor rotational speed $n$ are taken as the input parameters. Torque distribution coefficient is obtained as the output value through look-up table and interpolation.

Some conclusions can be drawn from the proportional distribution coefficient map:

(1) On different working conditions, in order to achieve the high efficiency performance, different distribution coefficients are demanded;

(2) In the low torque region, all the distribution coefficients equal 1, which shows that the FWD is applied as a better pattern when the torque demand is relatively small;

(3) In medium and high torque region, the distribution coefficients are 0.5 or slightly greater than 0.5 , which shows that $4 \mathrm{WD}$ can achieve higher efficiency;

(4) In the low speed region, there is almost no transitional area between the regions of distribution coefficient of 0.5 and 1 . That is because the isoefficiency curves are very dense in this area, which will lead to the sudden change in distribution coefficient map.

\subsection{Stability Control}

\subsubsection{Optimal Slip Ratio}

Tires at optimal slip ratio can make full use of the road driving ability. For actual vehicles and roads, optimal slip ratio is not a constant value. It changes due to the change of road conditions and 
its variation range is as much as $20 \%$. Thus, it is significant to find the optimal slip ratio in real time. Some papers simply set the optimal slip as a fixed point, such as the average value of optimal slip ratio on all kinds of roads or the optimal slip ratio in statistics. However, either way, these optimal slip ratios cannot ensure the optimum state of traction control system.

In this paper, the road conditions are classified into 10 levels, which are corresponding maximum tire/road friction coefficient $\mu$ from 0.1 to $1(0.1,0.2,0.3,0.4,0.5,0.6,0.7,0.8,0.9$ and 1$)$. According to the Tire test module in CarSim, tire characteristic simulation is carried out and the optimal slip ratio under different road friction coefficients is listed as Table 1.

Table 1. Road friction coefficient and the corresponding optimal slip ratio.

\begin{tabular}{ccccccccccc}
\hline Road Level & $\mathbf{1}$ & $\mathbf{2}$ & $\mathbf{3}$ & $\mathbf{4}$ & $\mathbf{5}$ & $\mathbf{6}$ & $\mathbf{7}$ & $\mathbf{8}$ & $\mathbf{9}$ & $\mathbf{1 0}$ \\
\hline Friction coefficient & 1 & 0.9 & 0.8 & 0.7 & 0.6 & 0.5 & 0.4 & 0.3 & 0.2 & 0.1 \\
Optimal slip ratio \% & 19 & 17 & 15 & 13.2 & 11.3 & 9.4 & 7.6 & 5.6 & 3.7 & 1.9 \\
\hline
\end{tabular}

\subsubsection{Road Friction Coefficient Estimation}

In Table 1, it can be seen that there is a one-to-one correspondence between road friction coefficient and the optimal slip ratio. In this paper, a Bayes' theorem-based iteration algorithm is applied to estimate the road adhesion coefficient [31].

At sampling time $t_{k}$, the estimated wheel slip ratio, longitudinal tire force and vertical force are expressed as $\hat{\lambda}, \hat{F}_{t}$ and $\hat{F}_{z}$, respectively, which could be identified by a dual extended Kalman filter (DEKF) proposed by Wenzel et al. [32]. Here, the estimated normalized driving factor is given as:

$$
\hat{\varphi}_{k}=\frac{\hat{F}_{t}}{\hat{F}_{z}}
$$

According to the tire model, with $\hat{\lambda}$ another normalized driving factor is obtained, denoted by $\varphi_{i, k}$, where $i$ stands for the road level from 1 to 10 . The error between $\hat{\varphi}_{k}$ and $\varphi_{i, k}$ is calculated as follows:

$$
e_{i, k}=\frac{\left|\varphi_{i, k}-\hat{\varphi}_{k}\right|}{\hat{\varphi}_{k}}, i=1,2,3, \ldots, 10
$$

The condition possibility of $\hat{\varphi}_{k}$ corresponding to different road levels is equivalent to the probability distribution of error $e_{i, k}$. The following likelihood function is obtained:

$$
p_{k}\left[\hat{\varphi}_{k} \mid \mu_{i}\right]=\frac{1}{\sqrt{2 \pi \sigma}} e^{-\frac{e_{i, k}^{2}}{2 \sigma^{2}}}, i=1,2,3, \ldots, 10
$$

where $\sigma$ is the standard deviation.

The prior probability that the road/tire coefficient equals to $\mu_{i}$ is $P_{k}\left(\mu_{i}\right)$. Then, we have:

$$
\sum_{i=1}^{10} P_{k}\left(\mu_{i}\right)=1
$$

On basis of Bayes' rule, under the condition that the estimated normalized driving factor is $\hat{\varphi}_{k}$, the posterior probability of the road/tire coefficient is expressed as follows:

$$
Q_{k}\left[\mu_{i} \mid \hat{\varphi}_{k}\right]=\frac{p_{k}\left[\hat{\varphi}_{k} \mid \mu_{i}\right] P_{k}\left[\mu_{i}\right]}{\sum_{i=1}^{10} p_{k}\left[\hat{\varphi}_{k} \mid \mu_{i}\right] P_{k}\left[\mu_{i}\right]}, i=1,2,3, \ldots, 10
$$


Then, at sampling time $t_{k}$, the road/tire friction coefficient could be estimated as:

$$
\hat{\mu}_{k}=\sum_{i=1}^{10} Q_{k}\left[\mu_{i} \mid \hat{\varphi}_{k}\right] \mu_{i}
$$

The next sampling time $t=t_{k+1}$, set $P_{k+1}\left[\mu_{i}\right]=Q_{k}\left[\mu_{i} \mid \hat{\varphi}_{k}\right]$, repeating the above above-mentioned process, the online road level estimation can be achieved. Finally, the optimal slip ratio is also derived according to the estimated friction coefficient.

\subsubsection{Optimal Slip Ratio Control}

In driving condition, wheel slip ratio is defined as:

$$
\lambda=\frac{\omega \cdot r-u}{u}
$$

It is apparent that in the low speed region, slip ratio in this equation is sensitive to the vehicle speed, which may leads to a large disturbance of the slip ratio calculation. Addressing this issue, in this paper, optimal SRC is achieved via the wheel rotational speed.

$$
\omega_{o}=\frac{u}{\left(1-\lambda_{o}\right) \cdot r}
$$

where $\lambda_{o}$ is the optimal slip ratio and $\omega_{o}$ denotes the corresponding rotational speed.

Then, a sliding mode controller is developed to make the actual wheel rotational speed $\omega$ track the optimal value $\omega_{o}$ described above. Then, the track error is defined as:

$$
e=\omega-\omega_{o}
$$

Define a switching function $s$ as follows:

$$
s=e+c \int e d t
$$

where $c$ is the constant switching function coefficient. Equation (21) represents the designed sliding surface. In this paper, exponential reaching law is selected and given as:

$$
\dot{s}=-k s-\varepsilon \operatorname{sgn}(s)
$$

where $k$ is the strictly positive constant gain and $\varepsilon$ is reaching velocity factor. By adjusting the parameters $k$ and $\varepsilon$ of the exponential reaching law, we can guarantee the dynamic quality of the process of sliding mode reaching and weaken the chattering existed in the SMC method.

Taking the derivative of Equation (21) and substituting into Equation (22) gives:

$$
-k s-\varepsilon \operatorname{sgn}(s)=\dot{e}+c e
$$

Then, the SMC law is derived by substituting Equation (3) into Equation (23):

$$
T_{o}=\frac{-\left[\varepsilon \operatorname{sgn}(s)+k s+c\left(\omega-\omega_{o}\right)\right] \cdot I+F_{t} \cdot r}{\text { beta }}
$$

where $T_{o}$ is defined as the torque which can make the tire reach the optimal slip ratio.

Additionally, the chattering of sliding mode controller is reduced using the following saturation function instead of sign function:

$$
\operatorname{sat}(s / \Phi)=\left\{\begin{array}{l}
s / \Phi \quad|s| \leq \Phi \\
\operatorname{sgn}(s) \quad|s|>\Phi
\end{array}\right.
$$


where $\Phi$ is a positive constant.

\subsection{Integrated Control Strategy}

The integrated control strategy aiming at the economy optimization and stability control is proposed based on the analysis of the driver desired torque, motor output and road adhesion capability.

The control system diagram is shown in Figure 5. As can be seen, the proposed integrated control strategy involves three parts: road level estimation, control input and control case selection.

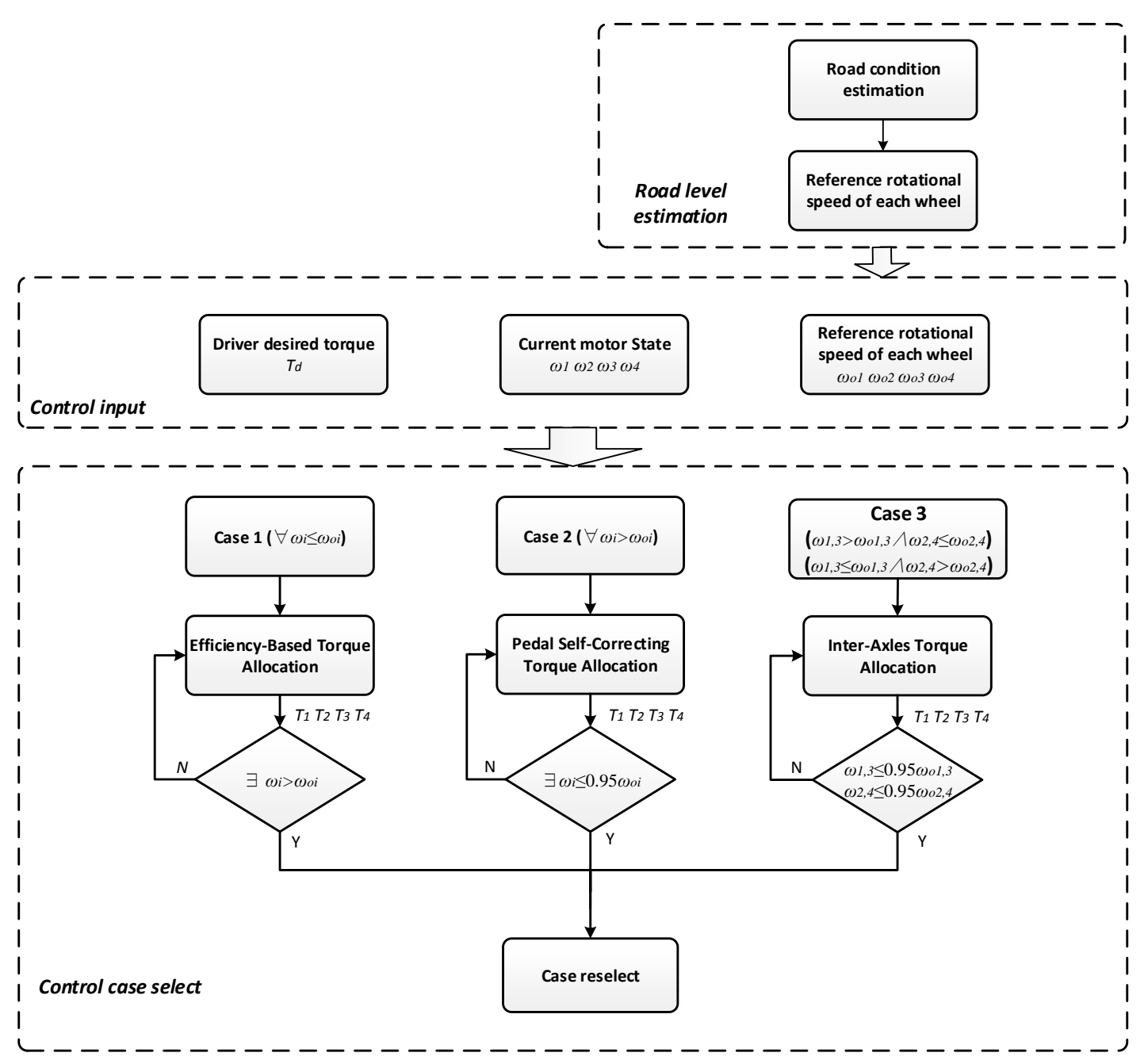

Figure 5. Structure of the integrated control strategy $(\forall$ : for all; $\wedge$ : or; $\exists$ : there exist).

Essentially speaking, road level estimation is to utilize Bayesian hypothesis selection to estimate the optimal slip ratio in real time. The results are then transferred to control input and case selection.

Control input is a part for signals acquisition and integration. These signals consist of driver desired torque signal, motor RPM signals, and reference wheel rotational speed. All of them will be shared with road level estimation and control case selection.

As for control case selection, it is the core of the proposed strategy. Three cases are designed and given as follows:

Case 1: economy-based traction allocation. Activation condition: for all $\omega_{i} \leq \omega_{o i}$, corresponding to high adhesion road. When a vehicle is traveling on this kind of surface, the traction for each tire offered by the road is greater than the actual motor output, which means in this situation no tire skid 
issues exists. Therefore, economy-based traction allocation is activated. The torque output for front and rear axle:

$$
\begin{gathered}
T_{f}=p \times T_{d} \\
T_{r}=(1-p) \times T_{d}
\end{gathered}
$$

Case 2: pedal self-correcting traction allocation. Activation condition: for all $\omega_{i}>\omega_{o i}$, corresponding to low adhesion road. When a vehicle is driving on a low adhesion road like snow road or even quick starts and stops on wet cement road, sometimes the road adhesion capacity cannot meet the driver's torque request, which will lead to tire's unstable skid. In order to avoid this situation, the acceleration pedal coefficient must be adjusted to a reasonable region to guarantee vehicle stability. Pedal self-correcting traction allocation is designed to keep actual wheel slip ratio at the optimal slip ratio point, to make the most of the road friction and to meet the driver desired torque as far as possible. In this case, the torque output for front and rear axle are given as:

$$
\begin{aligned}
T_{f} & =\frac{-\left[\varepsilon \operatorname{sgn}(s)+k s+c\left(\omega_{f}-\omega_{o f}\right)\right] \cdot I+F_{t f} \cdot r}{\text { beta }} \\
T_{r} & =\frac{-\left[\varepsilon \operatorname{sgn}(s)+k s+c\left(\omega_{r}-\omega_{o r}\right)\right] \cdot I+F_{t r} \cdot r}{\text { beta }}
\end{aligned}
$$

Case 3: inter-axles traction allocation. Activation condition: front wheels or rear wheels start to skid. It corresponds to intermediate adhesion road. In addition to high and low adhesion road, sometimes even though the total road adhesion is more than the driver desired torque, if the car is running on a joint road, the friction coefficient for front and rear wheels is different. Alternatively, due to the vehicle load distribution, the wheel with lower vertical load can only be applied with relatively small traction. Otherwise, it may lead to a seriously tire skid. Conversely, for the wheel with larger vertical load, it is necessary to moderately increase its motor torque output to make full use of the road capacity. For example, if the slip phenomenon occurs on front axle, the torque output for front and rear axle are:

$$
\begin{gathered}
T_{f}=\frac{-\left[\varepsilon \operatorname{sgn}(s)+k s+c\left(\omega_{f}-\omega_{o f}\right)\right] \cdot I+F_{t f} \cdot r}{\operatorname{beta}} \\
T_{r}=T_{d}-T_{f}
\end{gathered}
$$

By comparing different signals, a suitable control case will be activated and kept operating until the vehicle running condition changes.

Besides, due to the external disturbance or signal noise, there may be fluctuation during wheel speed control. In order to avoid case switching frequently, Case 1 will be terminated under the condition of there exits $\omega_{i}>\omega_{o i}$ which lasts for five motor control cycles $(50 \mathrm{~ms})$ and Cases 2 and 3 will be terminated when the rotational speed of the controlled wheel is smaller than $95 \%$ of the reference speed and lasts for five motor control cycles $(50 \mathrm{~ms})$.

\section{Simulation Results and Analysis}

The purpose of this section is to verify the proposed ITCS using computer simulations. Firstly, three control cases are evaluated separately in different simulation conditions. Then, variable road and desired torque conditions are applied to validate the integrated control strategy. The vehicle parameters are listed in the Table 2. 
Table 2. Vehicle parameters.

\begin{tabular}{ccc}
\hline Parameters & Values & Unit \\
\hline Vehicle mass & 1280 & $\mathrm{~kg}$ \\
Vehicle inertia about Z axis & 2460 & $\mathrm{~kg} \cdot \mathrm{m}^{2}$ \\
Distance of center of gravity (c.g.) from front axle & 1.2 & $\mathrm{~m}$ \\
Distance of c.g. from rear axle & 1.3 & $\mathrm{~m}$ \\
Frontal projected area & 2.1 & $\mathrm{~m}^{2}$ \\
Wheels track & 1.5 & $\mathrm{~m}$ \\
air resistance coefficient & 0.32 & - \\
Reducer ratio & 3.5 & - \\
Reducer efficiency & 0.9 & - \\
Tire radius & 0.3 & $\mathrm{~m}$ \\
Height of the sprung mass c.g. & 0.5 & $\mathrm{~m}$ \\
Wheel rotational inertia & 2.2 & $\mathrm{~kg} \cdot \mathrm{m}^{2}$ \\
\hline
\end{tabular}

\subsection{Simulation on Case 1: Economy-Based Traction Allocation}

This economy evaluation is carried out according to the New European Driving Cycle (NEDC). The four-wheel even torque drive (4WETD) and FWD are chosen to compare with the proposed ITCS. Figures 6 and 7 show the simulation results.

(a)

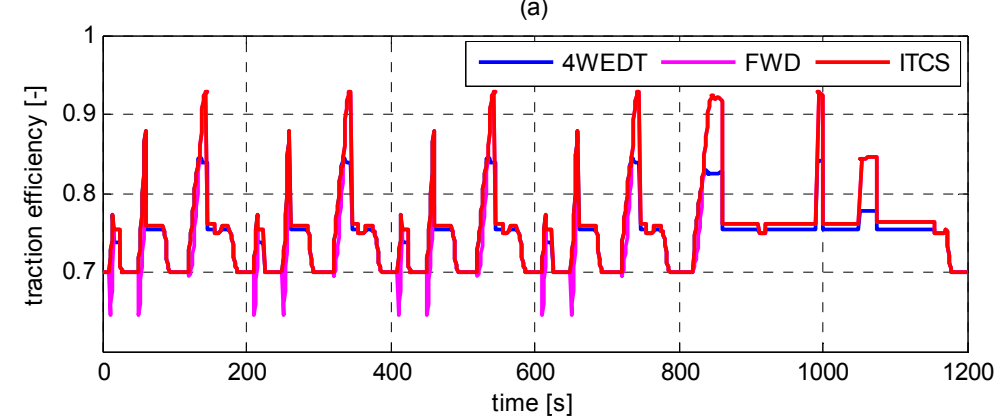

(b)

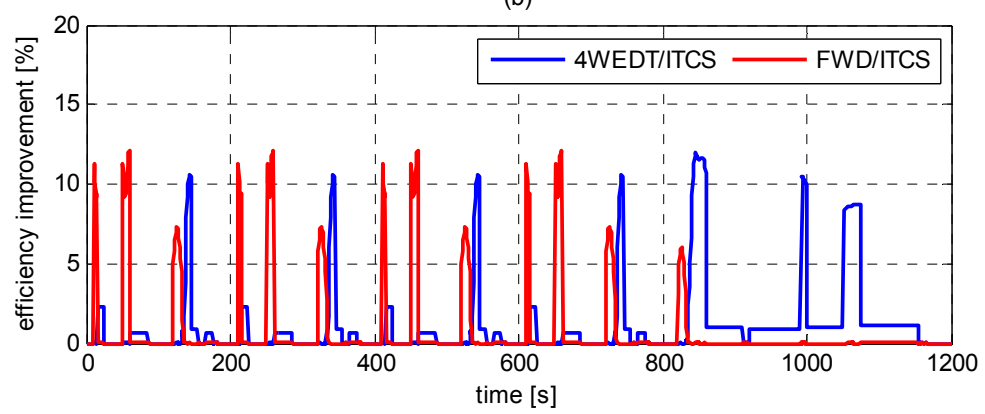

Figure 6. Efficiency and its improvement rate: (a) traction efficiency of different allocation approaches; and (b) efficiency improvement.

It can be seen from Figure 6 that vehicle traction efficiency is significantly improved after adopting ITCS. In some conditions, the improvement rate even reaches around $12 \%$. Besides, as Figure 7 shows, the ITCS also achieves lower thermal loss than the others, which can reduce motor's heat load and prolong its service life. 
(a)

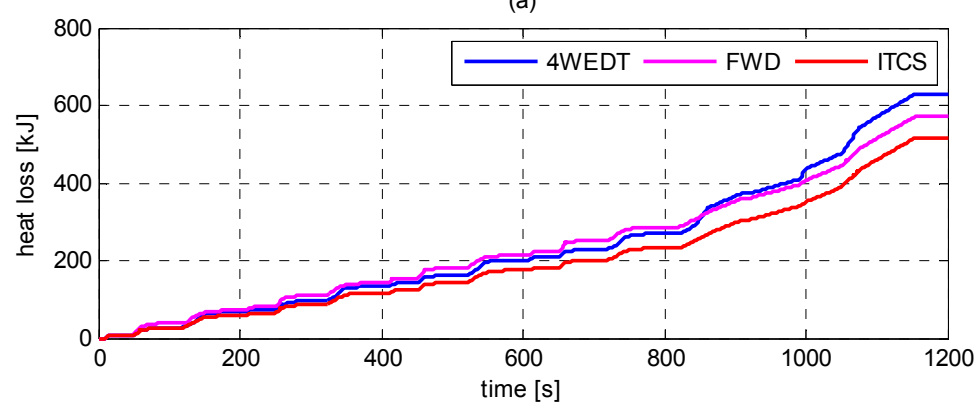

(b)

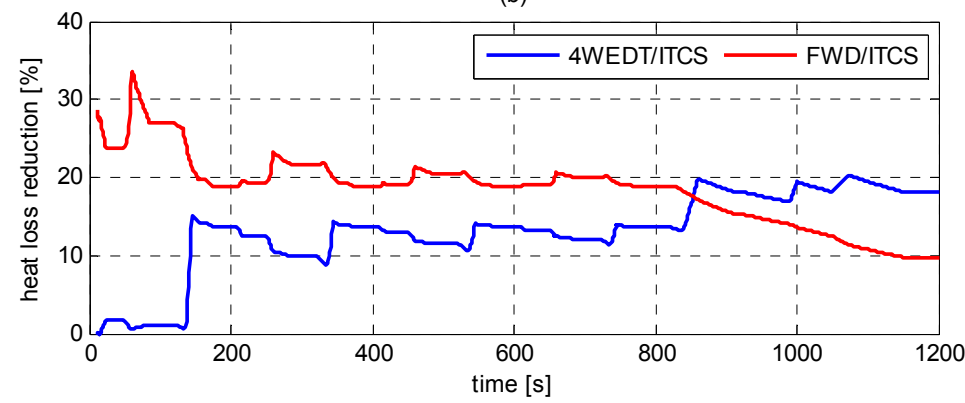

Figure 7. Heat loss and its reduction rate: (a) heat loss of different allocation approaches; and (b) heat loss reduction.

Table 3 lists the simulation results of economy improvement and equivalent weight reduction in each driving cycle stage. The highest energy saving occurs in high speed stage. ITCS decreases $4.632 \%$ energy consumption compared with 4WETD. Lowest energy saving, $0.134 \%$, also occurs in high speed stage but it is relative to FWD. As for the whole driving cycle, ITCS can decrease $3.584 \%$ and $1.992 \%$ energy consumption, respectively, by comparison to 4WETD and FWD. If we use weight to measure the energy saving effect, it means $47.02 \mathrm{~kg}$ and $26.11 \mathrm{~kg}$ weight reduction equivalently, which is difficult to achieve in engineering design phase.

Table 3. Improvement analysis among different traction allocation strategies. ITCS: integrated traction control strategy; 4WETD: four-wheel even torque drive; and FWD: front-wheel-drive.

\begin{tabular}{|c|c|c|c|c|c|}
\hline \multirow{2}{*}{ Cycle Stage } & \multicolumn{3}{|c|}{ Energy Consumption (kJ) } & \multirow{2}{*}{ Energy Saving } & \multirow{2}{*}{ Equivalent Weight Reduction (kg) } \\
\hline & \multicolumn{2}{|c|}{ Traditional Allocation } & ITCS & & \\
\hline \multirow{2}{*}{ Low Speed } & 4WETD & 1406.36 & \multirow{2}{*}{1373.35} & $2.347 \%$ & $30.91 \mathrm{~kg}$ \\
\hline & FWD & 1431.29 & & $4.048 \%$ & $53.04 \mathrm{~kg}$ \\
\hline \multirow{2}{*}{ High Speed } & 4WETD & 1658.66 & \multirow{2}{*}{1581.82} & $4.632 \%$ & $60.69 \mathrm{~kg}$ \\
\hline & FWD & 1583.95 & & $0.134 \%$ & $3.8 \mathrm{~kg}$ \\
\hline \multirow{2}{*}{ Whole Cycle } & 4WETD & 3065.02 & \multirow{2}{*}{2995.17} & $3.584 \%$ & $47.02 \mathrm{~kg}$ \\
\hline & FWD & 3015.24 & & $1.992 \%$ & $26.11 \mathrm{~kg}$ \\
\hline
\end{tabular}

\subsection{Simulation on Case 2: Pedal Self-Correcting Traction Allocation}

When simulated, the pedal signal is set at $70 \%$ opening. The tire/road friction coefficient equals 0.2 corresponding to wet hard packed snow road. Figures 8 and 9 show the results of the simulation experiment between pedal self-correcting traction allocation (with control) and even traction allocation (without control). During the whole time history, it is clear that the vehicle with pedal self-correcting traction allocation obtains better acceleration performance as shown in Figure 8a. Besides, it can be known from Figure 8d, the tires without control seriously slip, since the driver desired traction is greater than that provided by the road. By contrast, in Figures 8b, 9 and 10c, we can see that when the pedal self-correcting control is adopted, the accelerator pedal position signal adjusts rapidly from 
$70 \%$ opening to $65 \%$, the torque assigned to four wheels reduces immediately and then the slip ratio of each wheel is kept around the optimal point $3.7 \%$.

(a)

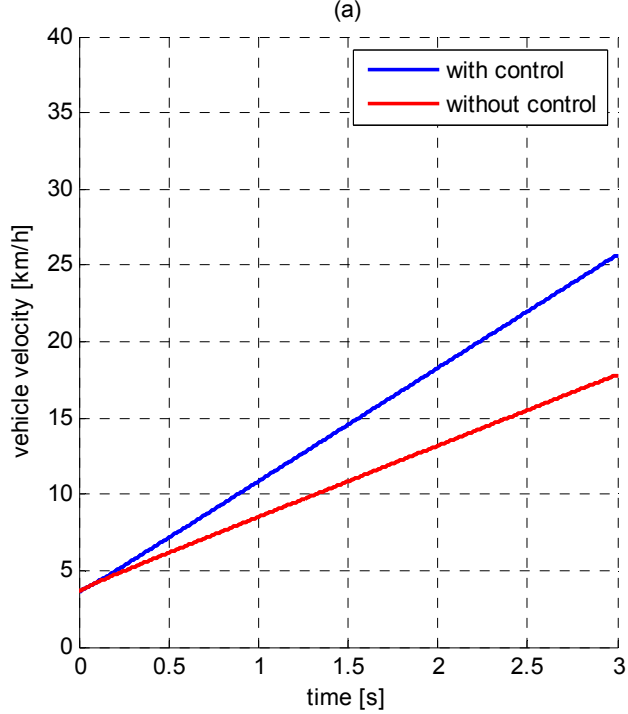

(c)

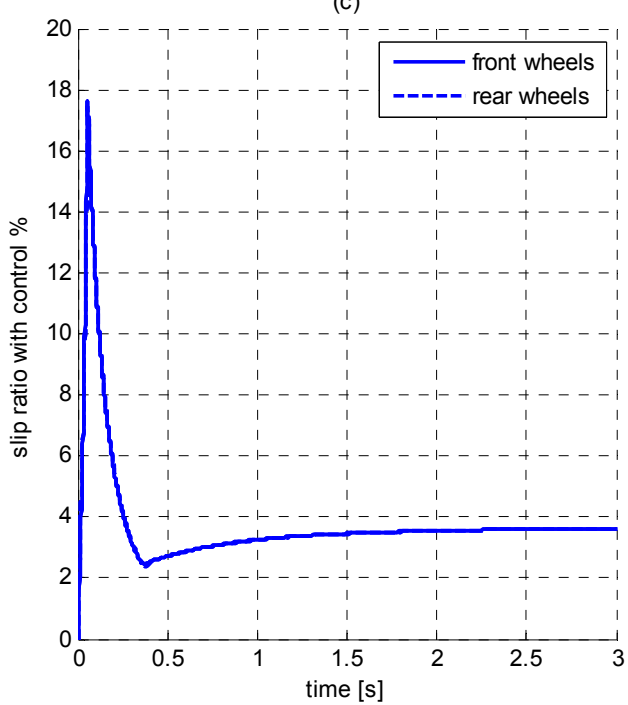

(b)

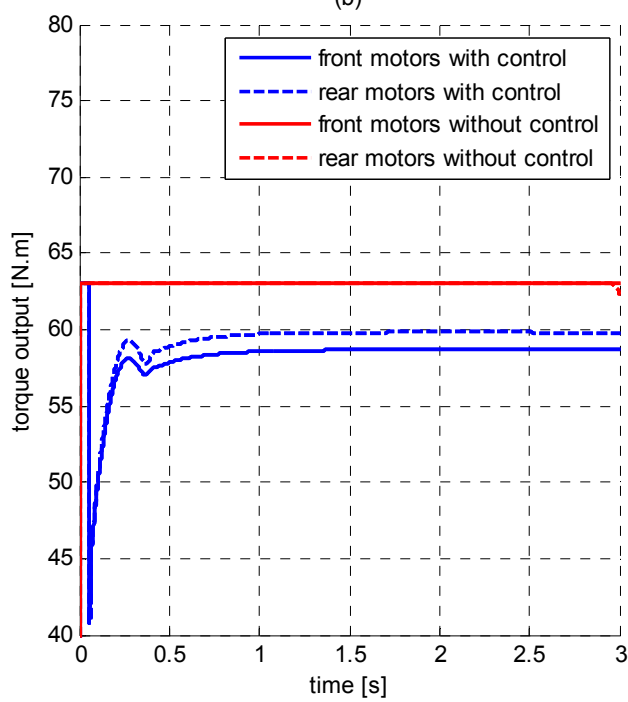

(d)

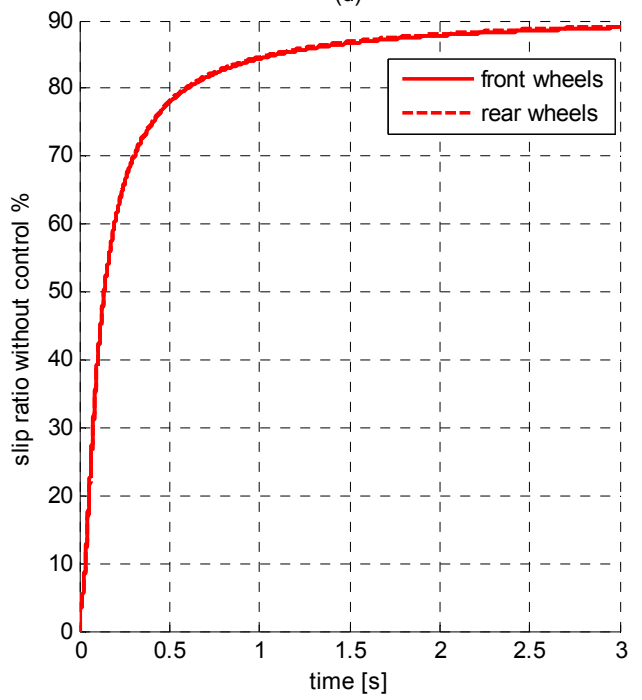

Figure 8. Simulation results of the vehicle with and without pedal self-correcting traction allocation: (a) vehicle velocity; (b) motor torque output; (c) wheel slip ratio with pedal self-correcting traction allocation; and (d) wheel slip ratio without control.

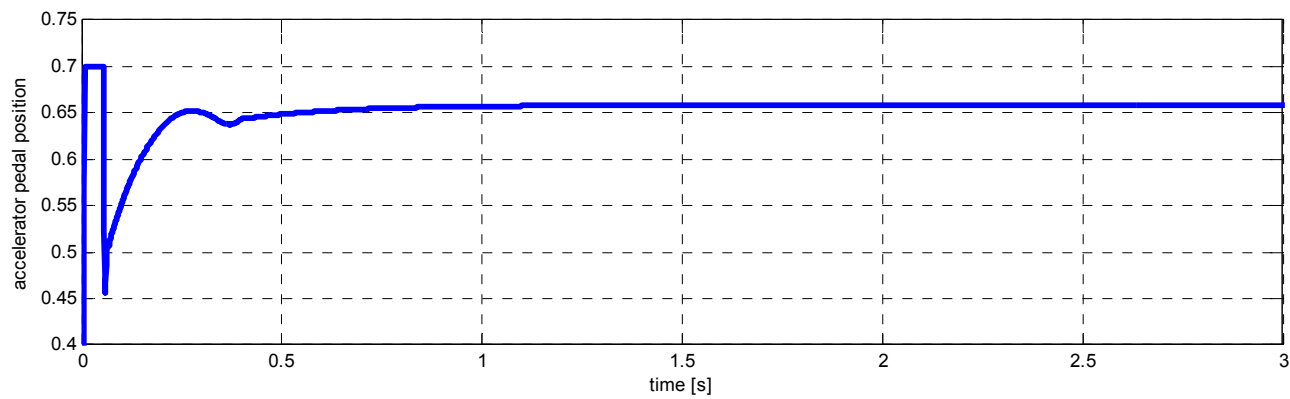

Figure 9. Accelerator pedal position under pedal self-correcting traction allocation. 
(a)

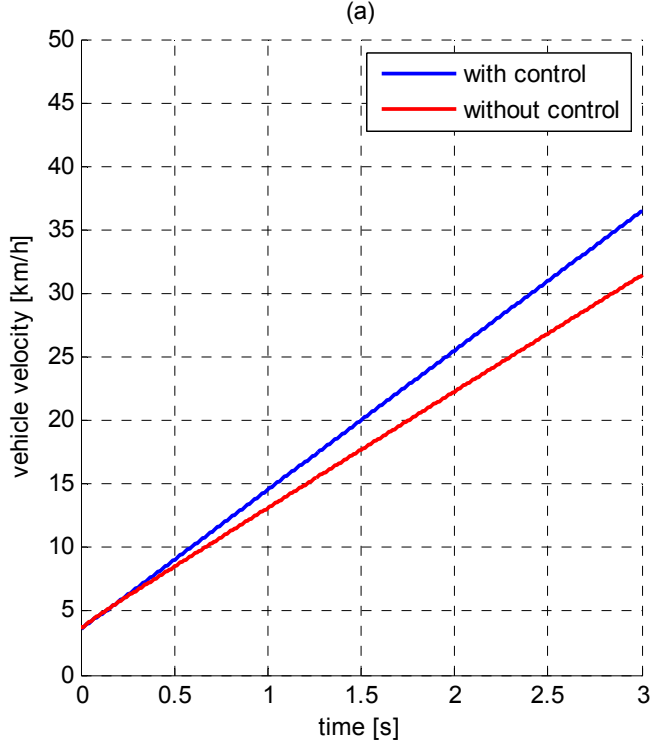

(c)

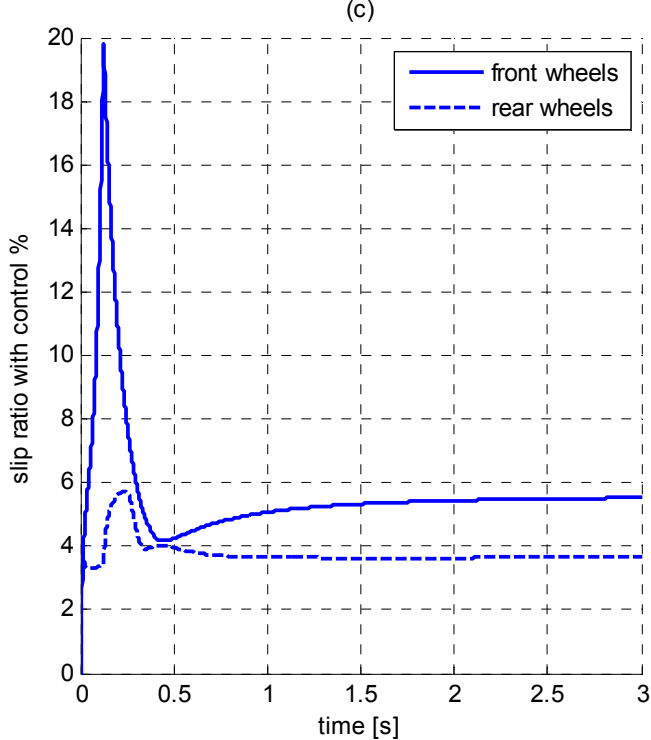

(b)

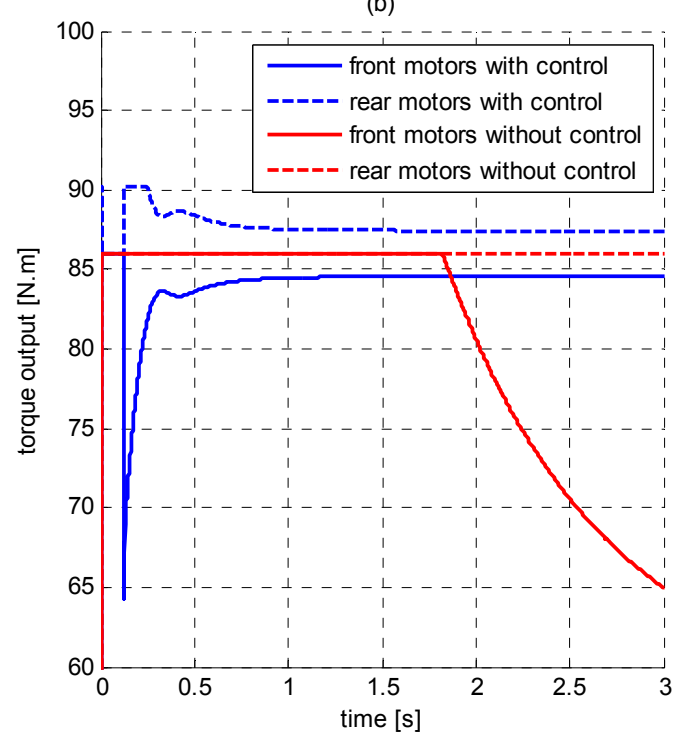

(d)

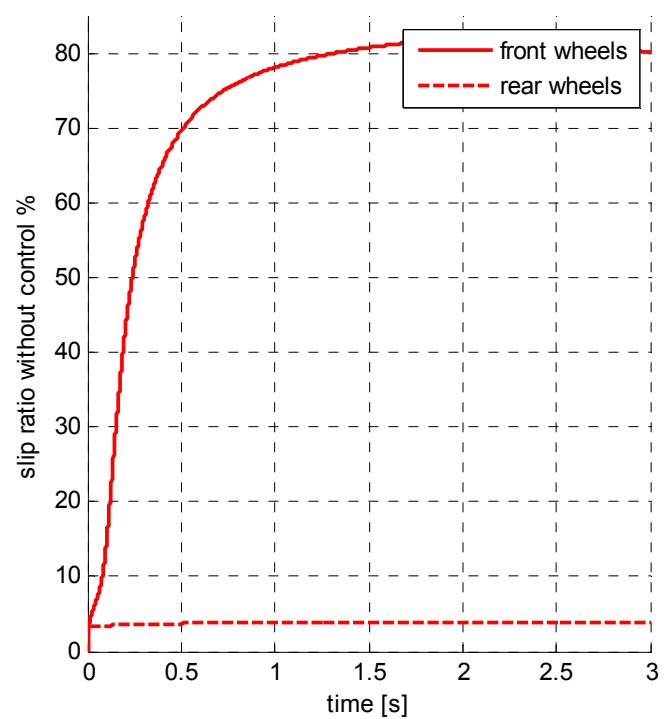

Figure 10. Simulation results of the vehicle with and without inter-axles traction allocation: (a) vehicle velocity; (b) motor torque output; (c) wheel slip ratio with inter-axles traction allocation; and (d) wheel slip ratio without control.

\subsection{Simulation on Case 3: Inter-Axles Traction Allocation}

In this simulation, the accelerator pedal position is set at $95 \%$ opening. The tire/road friction coefficient equals to 0.3 corresponding to slippery cement pavement. The simulation results of even traction allocation (without control) and inter-axle traction allocation strategy (with control) are shown Figure 10. In Figure 10a, obviously during the whole time history, the velocity of the vehicle with inter-axles traction allocation is higher than that without control. That means the proposed strategy enhances the vehicle acceleration performance, which results from the improvement of the road traction utilization. As shown in Figure 10d, the tire with high vertical load always remains steady. The tire with low vertical load, however, seriously skids. Its slip ratio even reaches more than $80 \%$. In contrast, Figure 10c clearly illustrates that the front wheel slip ratio with inter-axles traction allocation control reduces below optimal slip ratio 5.6\% within $0.5 \mathrm{~s}$ and reaches the steady value within $2 \mathrm{~s}$. It can be seen from Figure $10 \mathrm{~b}$ that there is a $20 \mathrm{Nm}$ fluctuation at simulation beginning, but the torque output 
stabilizes quickly after $0.5 \mathrm{~s}$. At the end of the simulation, the torque reduction in Figure $10 \mathrm{~b}$ is because the motor work point transfers from the constant torque area to constant power area.

\subsection{Simulation and Analysis on Variable Conditions}

In order to test the validity and robustness of the proposed control strategy, a compressive simulation experiment is additionally carried out under strongly varying conditions, which contains the switching of different road conditions and driver desired torque. The road surface input for front tires in this simulation is listed in Table 4. The time delay of the road switching for front and rear tires is also taken into consideration. In this simulation, the accelerator pedal position is set at $85 \%$ opening. After $9 \mathrm{~s}$, the vehicle velocity reaches $60 \mathrm{~km} / \mathrm{h}$ and then the accelerator pedal is released to $28 \%$ opening.

Table 4. Road surface input for front tires.

\begin{tabular}{ccc}
\hline Distance & Unit & Tire/Road Friction Coefficient \\
\hline $0-10$ & $\mathrm{~m}$ & 0.8 \\
$10-50$ & $\mathrm{~m}$ & 0.1 \\
$50-80$ & $\mathrm{~m}$ & 0.2 \\
$80-\mathrm{end}$ & $\mathrm{m}$ & 0.9 \\
\hline
\end{tabular}

As shown in Figure 11, during the first $2.3 \mathrm{~s}$, the car is running on a high adhesion road. The traction capacity provided by the road is much greater the driver desired torque. Therefore, Case 1 economy-based traction allocation is activated as shown in Figure 11g. According to current torque and RPM signals, the economy coefficient $p$ is set as 0.5 , which means even traction allocation is applied. Then, the front wheels move into the low adhesion area firstly and the rear wheels are still in the high adhesion area. The control case switches from Case 1 to Case 3 inter-axles traction allocation as shown in Figure 11g. Based on SMC, the torque output of front motors should be reduced to prevent the slip ratio from skidding. At the same time, the controller raises the rear motors output to ensure the vehicle dynamic performance to meet the driver's demand as shown in Figure 11c. When all four wheels move into the low adhesion road, Case 2 pedal self-correcting traction allocation is activated. At about $6.4 \mathrm{~s}$, the friction coefficient changes from 0.1 to 0.2, but Case 2 keeps running, since Case 2 is still satisfied. By the end of the simulation, the controller can estimate the optimal slip ratio correctly and choose appropriate control case. Furthermore, it should be noted that, after the accelerator pedal position decreases from $85 \%$ to $28 \%$ at the $8.9 \mathrm{~s}$, Case 1 is still running, however the front and rear motors' outputs are different the torque outputs from before. That is because through analysis of desired torque and RPM information, economy coefficient $p$ is reset as 1, FWD mode, to make the vehicle achieve the optimal economy performance.

Meanwhile, the control results from a slip ratio tracking controller is also presented as comparison and named SRTC. It can be seen from Figure 11e-h that, in the high friction road condition, the performance of ITCS and SRTC is similar and Case 1 is activated correctly. However, on low and intermediate adhesion roads, the disturbance of the slip ratio calculation leads to the frequent switch between Case 2 and Case 3. It apparently has negative effect on the controller performance. The comparative results demonstrate that the proposed integrated control strategy is adaptive to different road conditions, can improve driving efficiency, and ensure vehicle and wheel stability. 
(a)

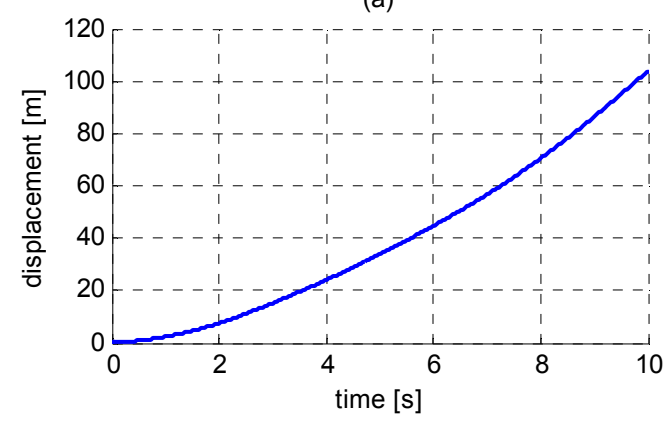

(c)

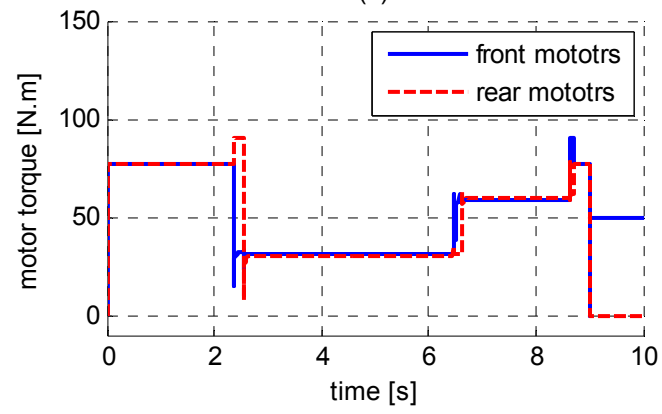

(e)

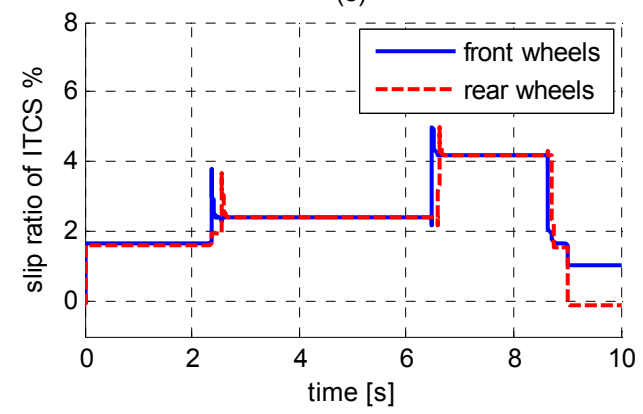

(g)

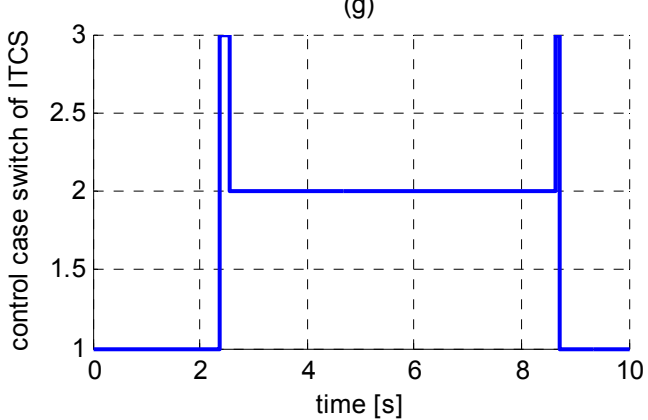

(b)

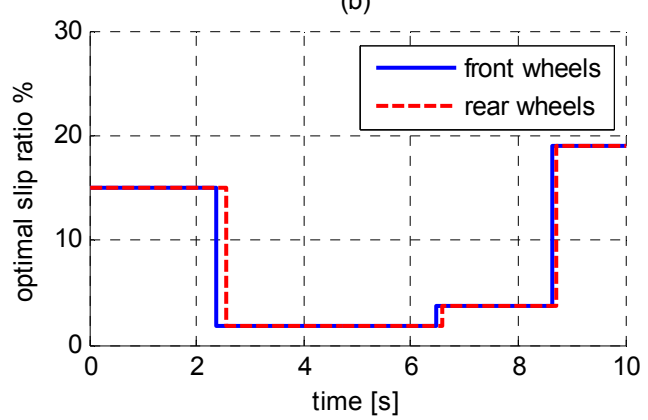

(d)

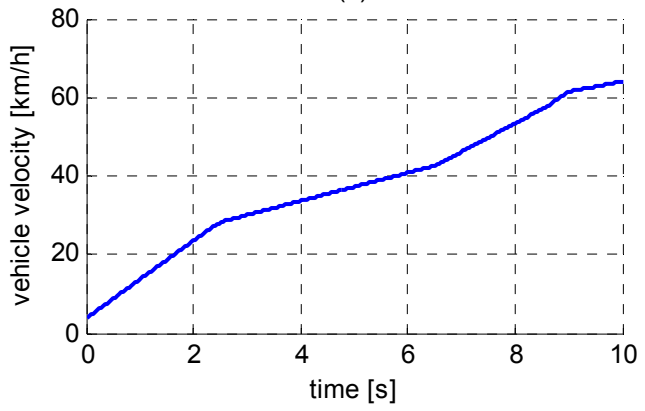

(f)

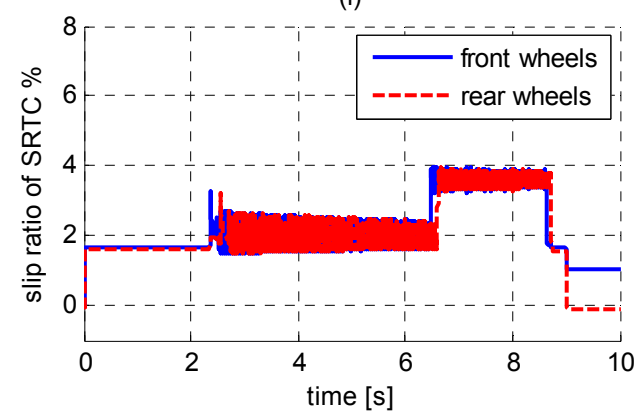

(h)

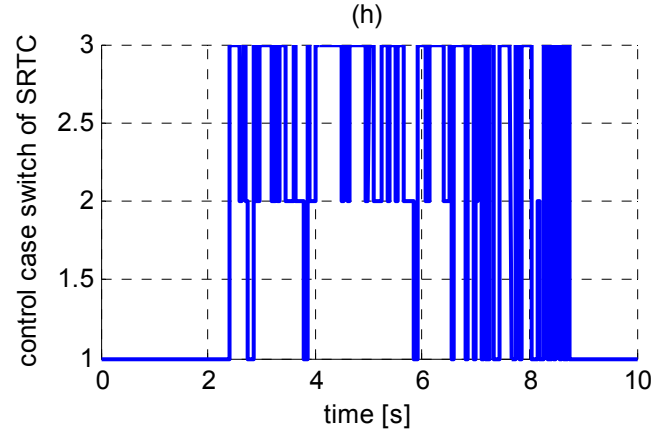

Figure 11. Simulation results on variable conditions: (a) longitudinal displacement of front wheels; (b) optimal slip ratio estimation; (c) motor torque output; (d) vehicle longitudinal velocity; (e) wheel slip ratio of ITCS; (f) wheel slip ratio of SRTC; (g) control case switch of ITCS; and (h) control case switch of SRTC.

\section{Conclusions}

In this paper, a novel ITCS for DDEVs is proposed, aiming at improving economy, vehicle stability and dynamic performance. Firstly, for the issue that the motor efficiency varies greatly in different working conditions, economy-based traction allocation strategy is developed. According to the economy coefficient, driver desired torque is distributed reasonably among four driving motors, which maximizes the motor driving efficiency and improves overall vehicle economy. Simulation results 
reveal that compared with 4WETD and FWD, the economy-based traction allocation can decrease energy consumption $3.584 \%$ and $1.992 \%$, respectively, according to the New European driving cycle. Meanwhile, pedal self-correcting traction allocation and inter-axles traction allocation is designed to overcome vehicle stability problems on low adhesion road. By means of Bayes theorem, optimal slip ratio on different road surfaces can be obtained in real time. Based on SMC, the torque output of each motor is adjusted to keep the wheel rotational speed under the reference value rapidly and stably. It is also verified that the tire skid phenomenon can be suppressed within $0.5 \mathrm{~s}$. On basis of the methods mentioned above, the integrated control strategy is finally presented. It can balance the relationship between road/tire friction conditions, motor efficiency and driver desired torque; and achieve vehicle economy and longitudinal stability optimization.

Further research may concentrate in the following aspects:

(1) When vehicle lateral motion is taken into account, the ITCS needs a good combination of the other stability control systems, such as electronic stability control (ESC).

(2) Since the proposed method is only analyzed theoretically and validated via simulation, an actual bench or field test is needed in the future to verify the proposed control strategy.

Acknowledgments: The work was supported by the Berlin City Vehicle (BCV) Project in Technical University of Berlin (TU-Berlin). The authors would like to thank China Scholarship Council (CSC) for providing a scholarship as the financial support for the first author to pursue his Ph.D. degree at TU Berlin. Finally, the authors also acknowledge support by the German Research Foundation and the Open Access Publication Funds of Technische Universität Berlin.

Author Contributions: Xudong Zhang and Dietmar Göhlich proposed the control strategy; Xudong Zhang programed and debugged the simulation experiments; Dietmar Göhlich contributed the simulation tools; all authors carried out data analysis, discussed results and contributed to write the paper.

Conflicts of Interest: The authors declare that there is no conflict of interests regarding the publication of this paper.

\section{References}

1. Hori, Y.; Toyoda, Y.; Tsuruoka, Y. Traction control of electric vehicle: Basic experimental results using the test EV “UOT Electric March”. IEEE Trans. Ind. Appl. 1998, 34, 1131-1138. [CrossRef]

2. Esmailzadeh, E.; Vossoughi, G.R.; Goodarzi, A. Dynamic modelling and analysis of a four motorized wheels electric vehicle. Int. J. Veh. Syst. Dyn. 2001, 35, 163-194. [CrossRef]

3. Fujii, K.; Fujimoto, H. Traction control based on slip ratio estimation without detecting vehicle speed for electric vehicle. In Proceedings of the Fourth Power Conversion Conference-Nagoya 2007, Nagoya, Japan, 2-5 April 2007; pp. 688-693.

4. Hori, Y. Future vehicle driven by electricity and control-research on four-wheel-motored "UOT Electric March II". IEEE Trans. Ind. Electron. 2004, 51, 954-962. [CrossRef]

5. Khatun, P.; Bingham, C.M.; Mellor, P.H. Comparison of Control Methods for Electric Vehicle Antilock Braking/Traction Control Systems; SAE Technical Paper No. 2001-01-0596; SAE International: Warrendale, PA, USA, 2001.

6. Ratiroch-Anant, P.; Hirata, H.; Anabuki, M.; Ouchi, S. Adaptive controller design for anti-slip system of EV. In Proceedings of the IEEE Conference on Robotics, Automation and Mechatronics, Bangkok, Thailand, 1-3 June 2006; pp. 1-6.

7. Deur, J.; Pavković, D.; Burgio, G.; Hrovat, D. A model-based traction control strategy non-reliant on wheel slip information. Int. J. Veh. Syst. Dyn. 2011, 49, 1245-1265. [CrossRef]

8. Bottiglione, F.; Sorniotti, A.; Shead, L. The effect of half-shaft torsion dynamics on the performance of a traction control system for electric vehicles. Proc. Inst. Mech. Eng. Part D J. Automob. Eng. 2012, 226, 1145-1159. [CrossRef]

9. Leiber, H.; Czinczel, A. Four Years of Experience with 4-Wheel Antiskid Brake Systems (ABS); SAE Technical Paper No. 830481; SAE International: Warrendale, PA, USA, 1983.

10. Zhao, Z. Research on Vehicle Dynamics, Its Nonlinear Control Strategies and Related Technologies. Ph.D. Thesis, Northwestern Polytechnical University, Xi'an, China, 2002.

11. Khatun, P.; Bingham, C.M.; Schofield, N.; Mellor, P.H. Application of fuzzy control algorithms for electric vehicle antilock braking/traction control systems. IEEE Trans. Veh. Technol. 2003, 52, 1356-1364. [CrossRef] 
12. Yin, D.; Oh, S.; Hori, Y. A novel traction control for EV based on maximum transmissible torque estimation. IEEE Trans. Ind. Electron. 2009, 56, 2086-2094.

13. Sakai, S.I.; Sado, H.; Hori, Y. Anti-skid control with motor in electric vehicle. In Proceedings of the 6th International Workshop on Advanced Motion Control, Nagoya, Japan, 30 March-1 April 2000; pp. 317-322.

14. Amodeo, M.; Ferrara, A.; Terzaghi, R.; Vecchio, C. Wheel slip control via second-order sliding-mode generation. IEEE Trans. Intell. Transp. Syst. 2010, 11, 122-131. [CrossRef]

15. Cho, K.; Kim, J.; Choi, S. The integrated vehicle longitudinal control system for ABS and TCS. In Proceedings of the IEEE International Conference on Control Applications (CCA), Dubrovnik, Croatia, 3-5 October 2012.

16. Tanelli, M.; Ferrara, A. Wheel slip control of road vehicles via switched second order sliding modes. Int. J. Veh. Des. 2013, 62, 231-253. [CrossRef]

17. Drakunov, S.; Özgüner, U.; Dix, P.; Ashrafi, B. ABS control using optimum search via sliding modes. IEEE Trans. Control Syst. Technol. 1995, 3, 79-85. [CrossRef]

18. Unsal, C.; Kachroo, P. Sliding mode measurement feedback control for antilock braking systems. IEEE Trans. Control Syst. Technol. 1999, 7, 271-281. [CrossRef]

19. He, H.; Peng, J.; Xiong, R.; Fan, H. An acceleration slip regulation strategy for four-wheel drive electric vehicles based on sliding mode control. Energies 2014, 7, 3748-3763. [CrossRef]

20. Nam, K.; Hori, Y.; Lee, C. Wheel Slip Control for Improving Traction-Ability and Energy Efficiency of a Personal Electric Vehicle. Energies 2015, 8, 6820-6840. [CrossRef]

21. Yuan, X.; Wang, J. Torque distribution strategy for a front-and rear-wheel-driven electric vehicle. IEEE Trans. Veh. Technol. 2012, 61, 3365-3374. [CrossRef]

22. Mokhiamar, O.; Abe, M. Active wheel steering and yaw moment control combination to maximize stability as well as vehicle responsiveness during quick lane change for active vehicle handling safety. Proc. Inst. Mech. Eng. Part D J. Automob. Eng. 2002, 216, 115-124. [CrossRef]

23. Mokhiamar, O.; Abe, M. How the four wheels should share forces in an optimum cooperative chassis control. Control Eng. Pract. 2006, 14, 295-304. [CrossRef]

24. He, P.; Hori, Y. Improvement of EV maneuverability and safety by disturbance observer based dynamic force distribution. In Proceedings of the EVS22 International Electric Vehicle Symposium and Exhibition, Yokohama, Japan, 23-28 October 2006.

25. Nishihara, O.; Kumamoto, H. Minimax optimizations of tire workload exploiting complementarities between independent steering and traction/braking force distributions. In Proceedings of the AVEC '06, International Symposium on Advanced Vehicle Control, Taipei, Taiwan, 20-24 August 2006; pp. 713-718.

26. Yamakawa, J.; Watanabe, K. A method of optimal wheel torque determination for independent wheel drive vehicles. J. Terramechanics 2006, 43, 269-285. [CrossRef]

27. Zareian, A.; Azadi, S.; Kazemi, R. Estimation of road friction coefficient using extended Kalman filter, recursive least square, and neural network. Proc. Inst. Mech. Eng. Part K J. Multi-Body Dyn. 2016, 230, 52-68. [CrossRef]

28. Guan, H.; Wang, B.; Lu, P.; Xu, L. Identification of maximum road friction coefficient and optimal slip ratio based on road type recognition. Chin. J. Mech. Eng. 2014, 27, 1018-1026. [CrossRef]

29. Zimmermann, M. Loss Calculation of an Electric Drive Train Using a Standard Driving Cycle. Master's Thesis, Technical University of Berlin, Berlin, Germany, 2013.

30. Zhang, X.; Göhlich, D.; Wu, X.L. Optimal torque distribution strategy for a four motorized wheels electric vehicle. In Proceedings of the EVS28 International Electric Vehicle Symposium and Exhibition, Goyang, Korea, 3-6 May 2015.

31. Ray, L.R. Real time determination of road coefficient of friction for IVHS and advanced vehicle control. In Proceedings of the American Control Conference, Seattle, WA, USA, 21-23 June 1995; Volume 3, pp. 2133-2137.

32. Wenzel, T.A.; Burnham, K.J.; Blundell, M.V.; Williams, R.A. Dual extended Kalman filter for vehicle state and parameter estimation. Int. J. Veh. Syst. Dyn. 2006, 44, 153-171. [CrossRef]

(C) 2017 by the authors; licensee MDPI, Basel, Switzerland. This article is an open access article distributed under the terms and conditions of the Creative Commons Attribution (CC BY) license (http:/ / creativecommons.org/licenses/by/4.0/). 